\title{
Antifungal activity of some medicinal plant extracts against some fungal isolates
}

Actividad antifúngica de algunos extractos de plantas medicinales contra algunos aislados de hongos.
Author:

Berivan A. Abdullah ${ }^{1}$

Diana T. Salih ${ }^{2}$

Asia A. M. Saadullah ${ }^{3}$

\section{SCIENTIFIC RESEARCH}

How to cite this paper:

Abdullah B A., Salih D T., and Saadullah A. A M., Antifungal activity of some medicinal plant extracts against some fungal isolates. Innovaciencia. 2019; 7 (1): 1-6.

http://dx.doi.org/10.15649/2346075X.506

Reception date:

Received: 25 January 2019

Accepted: 28 May 2019

Published: 25 October 2019

Keywords:

Plant extracts; fungal isolates; Antifungal activity.

\section{ABSTRACT}

Introduction: Fungi live everywhere in the environment, most of them are not dangerous, but some types of fungi can be harmful to human health. The medicinal plants contain many antimicrobial components that make them recently used as powerful drugs. The aim of the present investigation was to examine the antifungal potential and minimum inhibitory concentration (MIC) of three plant extract: Aloe vera gel, cinnamon (Cinnamomum zeylanicum) and turmeric (Curcuma longa) against three fungal species: Aspergillus niger, Candida albicans and Fusarium oxysporum. Materials and Methods: The plant materials were extracted using solvents DMSO and ethanol and then were tested against the selected fungal isolates using well diffusion method. Results and Discussion: Antifungal activity of Aloe vera against Aspergillus niger showed MIC value of $25 \%$ whereas for Candida albicans and Fusarium oxysporum the MIC obtained was 100\%. Both cinnamon and turmeric showed maximum potency against Aspergillus niger, Candida albicans and Fusarium oxysporum at highest MIC value of $100 \%$. The degree of inhibition increased correspondingly with increasing concentrations of the plant extracts. Conclusions: the tested plant extracts have an antifungal activity and could be used as alternative drugs.

\footnotetext{
Department of Biology, College of science, Duhok University, Kurdistan Region - Iraq. e-mail: berivan.abdullah@uod.ac.

Department of Biology, College of science, Duhok University, Kurdistan Region - Iraq.

Department of Biology, College of science, Duhok University, Kurdistan Region - Iraq, e-mail: asia.saadullah@uod.ac.
} 


\section{INTRODUCCTION}

The use of medicinal plants recently increased significantly and it's shown helpful for primary health care all over the world. Many plants contain antifungal, antibacterial, antiviral and anti-inflammation properties because it contains different kinds of secondary metabolites. Plant secondary metabolites are of low-molecular weight compounds such as phenolic compounds alkaloids, terpenoids, tannins, glycosides, organic acids, resins (including resin acids, resin alcohols and hydrocarbon resins), sugars (including starches, inulin, gums and phlegmatic, amino acids, proteins and enzymes, plant pigments (including chlorophyll, carotenoids, flavonoids, beet red bases and quinones) volatile oils and waxes, and

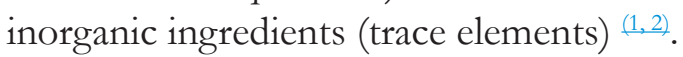

Plant extractions application and multiuse in medical setting has drawn many interests. Microbiologists have used the properties found in phytochemicals as potential antimicrobial drugs clinically. This is especially essential in understanding the alteration of traditional allopathic medical system. Many types of medicinal plants represent a rich source of different kinds of both antifungal and antibacterial agents. Different countries used different kinds of different medicinal plans as powerful drugs. Many parts of medicinal plants are extracting and used as raw drugs because they contain different medicinal properties. These parts include twigs, flowers, fruits, stem, roots and other modified organ of plants $\stackrel{(3,4)}{\text {. }}$.

The pathogenic fungi are usually plant, animal and human pathogens and are common in the environment .Fungi live either outdoors on plants and in soil or on many indoor surfaces as well as found on human skin and hair. Most fungi are not dangerous, but some types of fungi can be harmful to human health $\stackrel{(5,6)}{ }$.

The most common fungal species causing Aspergillosis is Aspergillus fumigatus, however, other species also can cause the disease such as Aspergillus niger, Aspergillus flavus and Aspergillus terreus ${ }^{(7)}$. Fusarium is one of the main opportunistic fungi; its toxicity is known by Fusariotoxicosis caused by Fusarium oxysporum in many animals. Candidiasis is an opportunistic infectious disease caused by the genus Candida, which includes different species. The most common species of the Candida is C. albicans. Due to the widespread and indiscriminate use of antimicrobial drugs, many microorganisms have developed resistance to specific types of these antimicrobial drugs and these strains are particularly obvious in the hospital environment, this problem also creates massive clinical problems in the treatment of infectious diseases $\stackrel{(8,9)}{\text {. }}$.

Repeated consumption of antifungal drugs leads to the development of more resistant fungi and increased damages of great amount of disease spread with side effects. Therefore, it is worthwhile to look for an alternative treatment such as extracting active compounds from many plant species that are used in herbal medicine $\stackrel{(10)}{\text {. }}$.

Most researches were dedicated to discover and study new natural sources that can suppress pathogenic fungi and replace chemical use of the antifungal agents $\stackrel{(11)}{\text {. }}$.

The objective of the research was to study the antifungal activity and minimum inhibitory concentration of three plant extract Aloe vera gel, cinnamon (Cinnamomum zeylanicum) and turmeric (Curcuma longa) against three fungal isolates Aspergillus niger, Fusarium oxysporum and Candida albicans.

\section{MATERIALS AND METHOD}

\section{Plant materials}

Mature leaves of Aloe (Aloe vera), turmeric rhizome (Curcuma longa) (Zingiberaceae family) and bark of cinnamon (Cinnamomum zeylanicum) were obtained from Duhok farms. These plants were botanically authenticated at the College of Agriculture, University of Duhok.

\section{Preparation of gel extract from Aloe vera.}

Mature, healthy and fresh leaves of Aloe vera were washed in the running tap water for $5 \mathrm{~min}$ and rinsed with sterile distilled water, then dissected longitudinally and the colourless parenchymatous tissue (aloe 
gel) was scraped out using a sterile knife without the fibres. The gel was ground with DMSO using the mortar and pestle. The extracts were filtered using Whatman No. 1 filter paper and the filtrate was centrifuged at $5000 \mathrm{RPM}$ for $5 \mathrm{~min}$. The supernatant was collected and stored in refrigerator at $4^{\circ} \mathrm{C} \underset{(12)}{\text {. }}$. Different concentration $(25 \%, 50 \%$ and $100 \%)$ of A. vera gel extract was prepared and subjected to antimicrobial studies.

\section{3-Preparation of Ethanolic Extract from cinna- mon and turmeric}

Sample Preparation Firstly, bark of cinnamon and Rhizomes of turmeric were washed and cut into small pieces. Bark of cinnamon and Rhizomes of turmeric were dried using drying cabinet under $40^{\circ} \mathrm{C}$ for 3-4 days. The dried plant material was grinded into powder form. $300 \mathrm{~g}$ of powdered Cinnamon bark and Rhizomes of turmeric were homogenized using $96 \%$ ethanol in a food processor, and then stirred magnetically overnight. The mixture filtrated and the filtrate was evaporated under vacuum to obtain ethanolic extract $\frac{(13)}{3}$. Different concentration $(25 \%-100 \%)$ of cinnamon and turmeric extract was prepared and subjected to antimicrobial studies.

\section{4-Fungal strains used}

The fungal species used in the present study were Candida albicans, Fusarium oxysporum and Aspergillus niger which obtained from mycology research lab in the college of science, University of Duhok and previously isolated and identified. Two isolates from each fungal species were tested in this investigation.

\section{The antifungal sensitivity test.}

The antifungal sensitivity of prepared plant materials were tested against the isolates of three fungal species, each isolate was subcultured before testing in a Sabouraud's Dextrose broth and incubated at $25^{\circ} \mathrm{C}$ for 24-48 hrs. Potato Dextrose Agar (PDA) medium was prepared and inoculated with $0.1 \mathrm{ml}$ of each of fungal isolates. The sensitivity test was performed using well diffusion method, for each plate a well of $6 \mathrm{~mm}$ in diameter was cut out of the agar using cork borer and filled with $0.1 \mathrm{ml}$ of the desired plant extract concentration and incubated at $25^{\circ} \mathrm{C}$ for $24-48$ hrs. $\stackrel{\text { (14) }}{ }$. The minimum inhibitory concentration was estimated as the lowest concentration of the plant extract that will inhibit the visible growth of a fungus after the incubation period.

\section{RESULTS}

The present study revealed the effectiveness of three plant extracts: Aloe vera, turmeric and cinnamon toward selected fungal isolates Aspergillus niger, Fusarium oxysporum and Candida albicans. Inhibitory effectiveness is varied depending on the type of plant extract and fungal isolate and in general had a high rate of diameters inhibition. DMSO gel extracts of A. vera were tested for the antifungal activity against the fungal species and the results are illustrated in the figure 1 and table 1.

The Aloe vera gel at concentration of $25 \%$ showed high suppression in the growth of Aspergillus niger while both Fusarium oxysporum and Candida albicans inhibited at the concentration of $100 \%$. The result of this study clearly reflect that Aloe vera has inherent ability to induce toxic effect on mycelial growth and proliferation of these fungi also Aloe vera gel contain saponin which is an soapy substance that has the antimicrobial properties against viruses, bacteria,

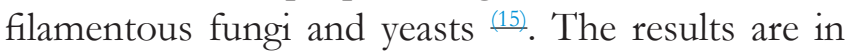
agreement with many findings $\frac{(16,17)}{\text {. }}$.

Table (1). MIC of Aloe Vera against fungal isolates.

\begin{tabular}{clc}
\hline No. & \multicolumn{1}{c}{ Fungal isolates } & $\begin{array}{c}\text { Aloe Vera } \\
\text { MIC (\%) }\end{array}$ \\
\hline 1 & Aspergillus niger (2) & 25 \\
2 & Fusarium oxysporum (2) & 100 \\
3 & Candida albicans(2) & 100 \\
\hline
\end{tabular}




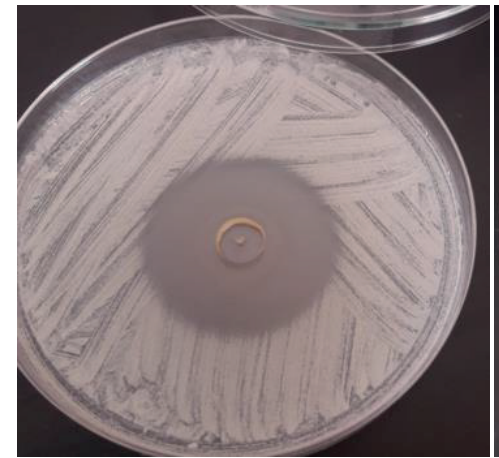

(A)

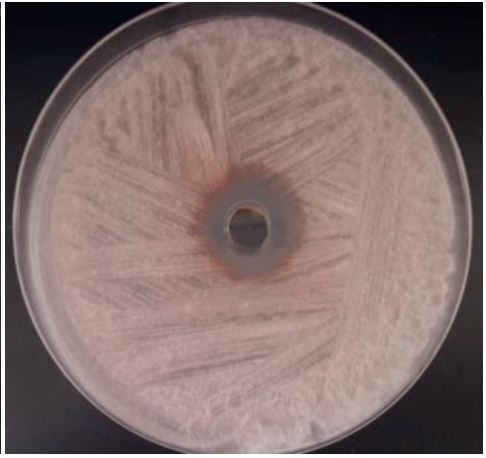

(B)

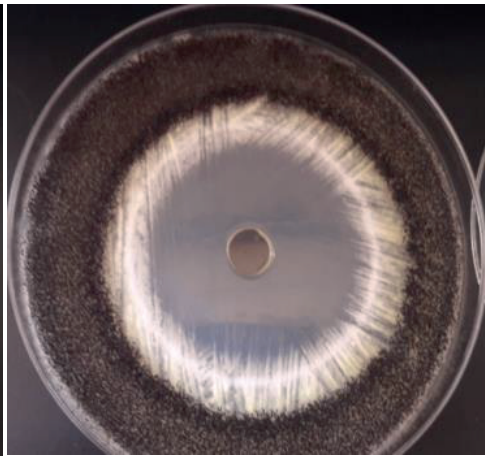

(C)

Figure 1. The inhibition zones by Aloe Vera with concentration $100 \%$ on different isolates: A. Candida albicans. B. Fusarium oxysporum and C. Aspergillus niger.

Antifungal activity of cinnamon against Candida albicans, Aspergillus niger and Fusarium oxysporum is given in table 2 and figure 2. Cinnamon showed complete inhibition against three tested fungi at the concentration of $100 \%$.The good potential of cinnamon as antifungal agent was reported previously by many studies $\frac{(18-21)}{\text {. }}$.
Antimicrobial activity of cinnamon has been reported to inhibit the growth of yeasts, molds, and bacteria $\stackrel{(22)}{2}$. The main component of cinnamon is cinnamaldehyde which contains aldehyde group and conjugated double bond outside the ring. Cinnamaldehyde is a powerful antifungal agent effect on fungal cell wall component $(1,3)$ - glucan and chitin synthesis in molds and yeasts $\stackrel{(23,24)}{ }$.

Table 2. MIC of Cinnamon (Cinnamomum zeylanicum) against fungal isolates.

\begin{tabular}{clc}
\hline No. & \multicolumn{1}{c}{ Fungal isolates } & $\begin{array}{c}\text { Cinnamon (Cinnamomum zeylanicum) } \\
\text { MIC (\%) }\end{array}$ \\
\hline 1 & Aspergillus niger (2) & 100 \\
2 & Fusarium oxysporum (2) & 100 \\
3 & Candida albicans(2) & 100 \\
\hline
\end{tabular}

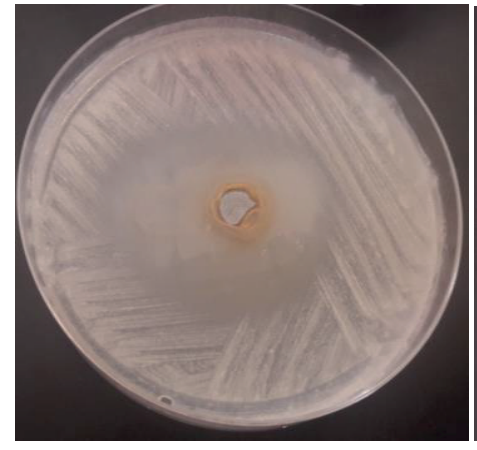

(A)

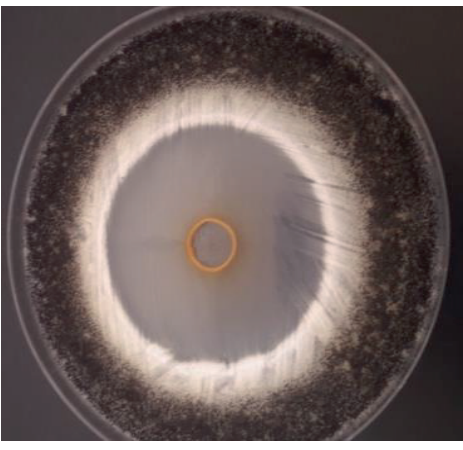

(B)

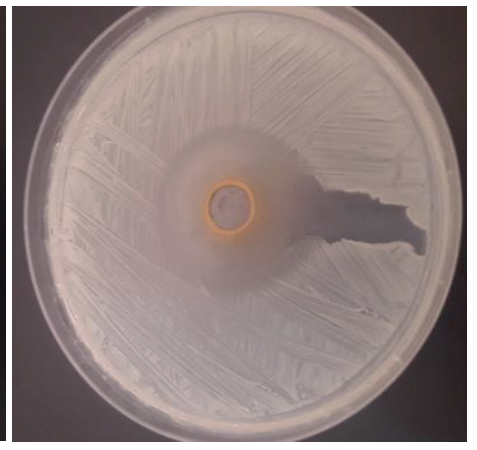

(C)

Figure 2. The inhibition zones by Cinnamon (Cinnamomum zeylanicum) at concentration $100 \%$ on different isolates: A. Fusarium oxysporum B. Aspergillus niger and C. Candida albicans. 
In the present investigation, in vitro antifungal activity of the DMSO extracts of turmeric was quantitatively evaluated according to the zone of inhibition. The concentration of $100 \%$ DMSO extracts of turmeric studied in the present investigation exhibited inhibitory effect against the three selected hu- man fungal pathogens (Table and figure 1). Because of the traditional extensive use of turmeric in food products, many researchers have been done to study the turmeric to controlling fungal causing spoilage and fungal pathogens $\stackrel{(25)}{\text {. }}$

Table 3. MIC of Turmeric (Curcuma longa) against fungal isolates.

\begin{tabular}{|c|c|c|}
\hline & & Turmeric (Curcuma longa) \\
\hline No. & Fungal isolates & MIC $(\%)$ \\
\hline 1 & Aspergillus niger (2) & 100 \\
\hline 2 & Fusarium oxysporum (2) & 100 \\
\hline 3 & Candida albicans(2) & 100 \\
\hline
\end{tabular}

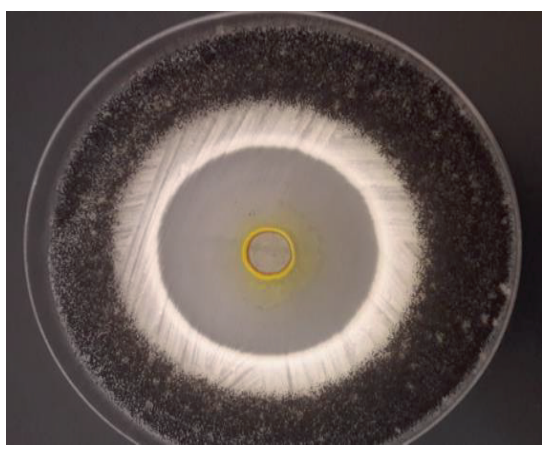

A

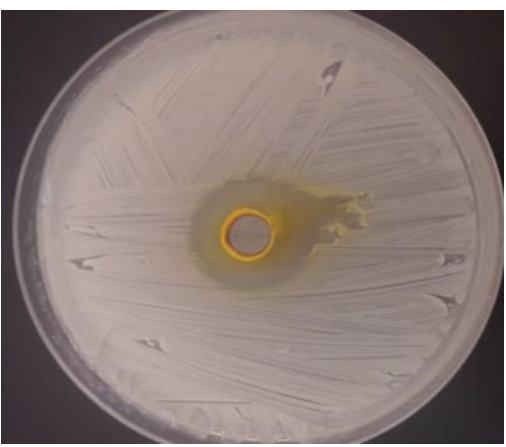

B

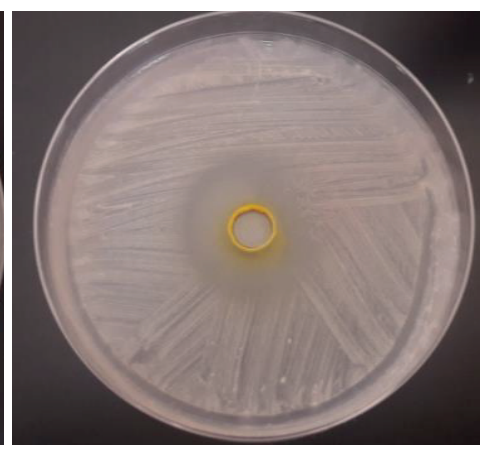

C

Figure 3. The inhibition zones by Turmeric (Curcuma longa) with concentration $100 \%$ on different isolates: A. Aspergillus niger, B. Candida albicans, C. Fusarium oxysporum.

\section{CONCLUSIONS}

We conclude from the current study the antifungal activity of three tested plant extracts showed prominent antifungal activity against the fungal isolates Aspergillus niger, Candida albicans and Fusarium oxysporum and contain more active compounds allowing recommended therapeutic alternatives to antifungal chemical agents in addition the plants extracts are source of cheap antifungal.

\section{REFERENCES}

1. Hadacek, F. Secondary Metabolites as Plant Traits: Current Assessment and Future Perspectives. Crit. Rev. Plant Sci. 2002; 21(4): 273-322. https://doi.org/10.1080/0735-260291044269
2. Rawal, P. and Adhikari R. S. Evaluation of antifungal activity of Zingiber officinale against Fusarium oxysporum f. sp. lycopersici. 2016; 7(2):5-9.

3. Uniyal, S.K., Singh, K.N., Jamwal, P. and Lal, B. Traditional use of medicinal plants among the tribal communities of Chhota Bhangal, Western Himalayan. J. Ethnobiol. Ethnomed. 2006; 2: 1-14. https://doi.org/10.1186/1746-4269-2-14

4. Mahesh, 1.B. and Satish, S. Antimicrobial Activity of Some Important Medicinal Plant against Plant and Human Pathogens. World Journal of Agricultural Sciences. 2008; 4: 839-843.

5. Hawksworth, D.L. The magnitude of fungal diversity: the 1.5 million species estimate revisited. Mycol. Res. 2001; 105:1422-1432.

https://doi.org/10.1017/S0953756201004725 
6. Garcia-Solache, M.A., and Casadevall, A. Global warming will bring new fungal diseases for mammals. M.Bio. 2010; 1(1): 1-3. https://doi.org/10.1128/mBio.00061-10

7. Saddiq, A A N. Antiagnostic effect of musk and sidr leaves on some of the opportunistic fungi that cause Lung toxicity. Life Science Journal. 2014; 11(2s):99-108.

8. Evan's, W.C. Trease and Evan's pharmacognosy. 14th Edn., W.B. Saunders Company Ltd, London. 1999.

9. Davis, J. Inactivation of antibiotics and the dissemination of resistance genes. Science. 1994; 264: 375-382.

https://doi.org/10.1126/science. 8153624

10. Hassawi, D. and Kharma, A. Antimicrobial activity of some medicinal plants against Candida albicans. J. Biol. Sci. 2006; 6(1):109-114.

https://doi.org/10.3923/jbs.2006.109.114

11. AL-Jobori K. M. M., AL- Ameed A. I., Witwit N.M. In vitro Antifungal Activity of Musk. BEPLS. 2015; 4(11): 38-44.

12. Pugh, N., Ross S. A., Elsohly, M. H. and Pasco D. S. Characterizations of Aloeride, new high molecular weight polysaccharides from Aloe vera with potent immunostimulatory activity. J Agri Food Chem. 2001; 49(2): 1030-1034.

https://doi.org/10.1021/jf001036d

13. Banso, A. Phytochemical and antibacterial investigation of bark extracts of Acacia nilotica. Journal of Medicinal Plant Research. 2009; 3 (5): 8285.

14. Magaldi, S., Mata-Essayag, S., Hartung de Capriles, C., Perez, C., Colella, M.T., Olaizola, C., and Ontiveros, Y. Well diffusion for antifungal susceptibility testing. Inter. J. Infec. Dis. 2004; 8:39-45. https://doi.org/10.1016/j.ijid.2003.03.002

15. Atherton, P. Aloe vera Myth or Medicine? Positive Health Publications, Denmark, Europe. 2002.

16. Coopoosamy, R.M and M.L. Magwa. Traditional use, antibacterial activity and antifungal activity of crude extract of Aloe excelsa. African Journal of Biotechnology 2007; 6(20): 2406-2410. https://doi.org/10.5897/AJB2007.000-2377

17. Arunkumar, S. and Muthuselvam, M. Analysis of phytochemical constituents and antimicrobial activities of Aloe vera L. against clinical pathgens. World Journal of Agricultural Sciences. 2009; 5(5): 572-576.
18. Azzouz, M. A. and Bullerman,L. R. Comparative antimycotic effects of selected herbs and spices, plant components and commercial antifungal agents. J. Food Protect. 1982; 45: 1248-1301.

https://doi.org/10.4315/0362-028X-45.14.1298

19.Soliman, K.M. and Badea, R.I. Effect of oil extracted from some medicinal plants on different mycotoxigenic fungi. Food Chem Toxicol. 2002; 40: 1669-1675.

https://doi.org/10.1016/S0278-6915(02)00120-5

20.Velluti, A. Sanchis, V. Ramos, A.J. Egido, J. and Marin, S. Inhibitory effect of cinnamon, clove, lemongrass, oregano and palmarose essential oils on growth and fumonisin B1 production by $\mathrm{Fu}$ sarium proliferatum in maize grain. J. Food Microbiol. 2003; 89: 145-154.

https://doi.org/10.1016/S0168-1605(03)00116-8

21.Singh, G. Maurya, S. DeLampasona, M.P. and Catalan, C.A. A comparison of chemical, antioxidant and antimicrobial studies of cinnamon leaf and bark volatile oils, oleoresins and their constituents. Food Chem. Toxicol. 2007; 45(9): 1650 1661. https://doi.org/10.1016/i.fct.2007.02.031

22.Matan, N., Rimkeeree, H. Mawson, A.J. Chompreeda,P. Haruthaithanasan, V., and Parker, M. Antimicrobial activity of cinnamon and clove oils under modified atmosphere conditions. J. Food Microbiol. 2006; 107: 180 - 185.

https://doi.org/10.1016/j.ijfoodmicro.2005.07.007

23. Wang, S.Y., Chen P.F. and Chang, S.T. Antifungal activities of essential oils and their constituents from indigenous cinnamon (Cinnamomum osmophloeum) leaves against wood decay fungi Bioresour. Technol. 2005; 96: 813-818.

https://doi.org/10.1016/j.biortech.2004.07.010

24.Bang, K.H. Lee, D.W. Park, H.M. and Rhee,Y.H. Inhibition of fungal cell wall synthesizing enzymes by transcinnamaldehyde. Biosci. Biotech. Biochem. 2000; 64: 1061-1063.

https://doi.org/10.1271/bbb.64.1061

25.Dovigo,L. N. Pavarina, A. C. Carmello, J. C. MacHado, A. L. Brunetti, I.L. and Bagnato, V. S. Susceptibility of clinical isolates of Candida to photodynamic effects of curcumin. Lasers in Surgery and Medicine. 2011; 43(9): pp. 927-934. https://doi.org/10.1002/1sm.21110 